\title{
Information system for railway energy management
}

\author{
G. Hribar ${ }^{1}$, B. Dremelj ${ }^{2} \&$ M. Sekavčnik ${ }^{3}$ \\ ${ }^{1}$ Genera Lynx d.o.o, Slovenia \\ ${ }^{2}$ Slovenian Railways, Slovenia \\ ${ }^{3}$ Faculty of Mechanical Engineering, University of Ljubljana, Slovenia
}

\begin{abstract}
The energy market and railway transport have been opening up. One of the first European railway operators to respond to the changed conditions was the Holding Slovenske železnice (HSŽ, Slovenian Railways), constructing a comprehensive data reading and energy management system.

The presented system gives its users the ability to control the consumption on the site of supply and also on the site of usage. The system includes the supply grid and power substations, railway stations and other infrastructural objects, as well as energy usage readings from rail vehicles. Rail vehicles are equipped not only with energy meters but also with GPS and GPRS communication devices to transfer data into the energy management system in near-real time. This makes the equipment useful for billing and for lowering energy related costs. The data exchange with the traffic management system enables energy consumption forecasting and the optimisation of energy usage.

This article presents existing features and proposes the development of a complex railway energy management system. As a case study of collected data usage initial analyses on drivers' behaviour with the focus on coasting control and energy efficient driving strategy are presented.
\end{abstract}

Keywords: railways, information system, energy management, metering, on-board device, coasting.

\section{Introduction}

European electricity market has undergone structural changes in the past few years. Market liberalization, which now at least on paper becomes a fact for 
bigger energy consumers in all EU members' states, brings more challenges than suppliers hoped, but less easy-saving- opportunities than consumers wished. In fact market prices in spite of established competition and freedom of choice after a short fall in the beginning now rise again. One reason is an increasing energy demand in the $\mathrm{EU}$, another is a stricter emission regulation and the established emission allowances market, whose price per ton of $\mathrm{CO}_{2}$ rose above all expectations. Although environmentally friendly, railways were hit by additional costs of emission trading more than other modes of transport.

To cope with those challenges energy consumers need much more information than in the era before the market opening. Cost reduction nowadays can be assured not only with lowering energy consumption, but also with efficient negotiation with the energy supplier for best supply conditions. For this the consumer needs to know the load profile of past and future energy consumption.

Improvement of energy efficiency is another way of lowering energy related costs. But this cannot be done without precise measurement and evaluation of present consumption, regarding all influence factors.

On the other hand the railway section itself faces great changes. Liberalization of railways services demands adaptation of existing service providers and also of infrastructure managers, which are not exposed to competition, but they need to be able to charge the network fees based on transparent and non-discriminatory rules to foreign operators. At the same time they should earn a reasonable return on its assets to assure adequate maintainance and development of railways infrastructure. Energy related costs are a significant cost factor of railways operation. In the case of an electrified railway network an infrastructure manager is responsible for the supply of energy. The infrastructure manager also must allocate energy consumption for each single train.

To face both challenges, rising prices of electricity and energy market opportunities on one side and liberalization of the railway section on the other, Slovenian Railways implemented an information system for energy management. The system collects data from all power substations for railway grid supply and bigger infrastructure consumers. Beside this, a pilot project of on-board electricity consumption and location metering was implemented and evaluated.

This article presents the development and implementation of the information system. A special focus is given to on board data collection and communication solutions. Another area covered in the article is evaluation of data collected and their usability for lowering of energy related costs.

\section{Slovenian railways infrastructure and traction units}

\subsection{Infrastructure}

Slovenian Railway lies on the crossroad of the $5^{\text {th }}$ and $10^{\text {th }}$ European transport corridor. Yearly volume of cargo traffic is $6.4 \mathrm{~m}$ gross ton kilometres and is 
rising 5\% per year. A large part of cargo traffic represents transportation from the port Koper to eastern and northern Europe.

Approximately $500 \mathrm{~km}$ of main lines are electrified. Power supply is assured through 17 substations, which transform electricity from the public electricity network to $3000 \mathrm{~V}$ DC.

\subsection{Engines}

Most of the cargo trains on the main lines are hauled with engines type 342, type 362 and type 363.

Table 1: $\quad$ Engines properties.

\begin{tabular}{|l|l|l|l|l|}
\hline & & 363 & 342 & 362 \\
\hline manufacturer & & Alsthom & Asgen & Ansaldo \\
\hline power (cont.) & $\mathrm{kW}$ & 2750 & 1880 & 2640 \\
\hline power (one hour) & $\mathrm{kW}$ & 2830 & 2280 & 3150 \\
\hline mass & ton & 115 & 82 & 113 \\
\hline heating power & $\mathrm{kW}$ & 990 & 1050 & 1050 \\
\hline
\end{tabular}

All engines are supplied with $3000 \mathrm{~V}$ DC voltage. The engines observed do not have possibility to recuperate energy.

Energy meters were installed as part of the pilot project and are mounted for a longer period so the installed devices did not have an influence on driver behaviour.

\section{Measurements and data transfer}

\subsection{Network and infrastructure consumption}

To retrieve data from the power substations on network and infrastructure consumption, the existing automatic meters reading (AMR) software Iskraemeco SEP2 is used. All power substations meters are equipped with phone modems. AMR software calls them once per day and collects data.

The network electricity usage profile is available in 15 minutes resolution.

\subsection{Traction units consumption}

\subsubsection{Equipment}

A data logging and communication device GSMBOX-R, produced by Genera Lynx, holds energy meter LEM EMT4, GPRS communication device GORLITZ Skalar and power supply. The device is mounted in the cabin of the engine.

Garmin GPS sensor with integrated embedded receiver and antenna is mounted on the roof of the engine. 


\subsubsection{Data collection and communication}

Data collection from the energy meter is performed by regular reading of the serial port of the communication device. The created file in the communication device contains the profile of energy flow on the pantograph for active energy, reactive energy and recuperated energy in one minute resolution.

The Garmin GPS sensor feeds data of UTC time, latitude, longitude, hemisphere and speed over ground.

The communication device connects in regularly every few minutes interval to the private GPRS network. It sends data files through VPN connection into the application EGIDA, a product of Genera Lynx. EGIDA runs on a central server, collects the data and writes them into an SQL database. The application confirms receiving of the data and the data on board are flagged as sent.

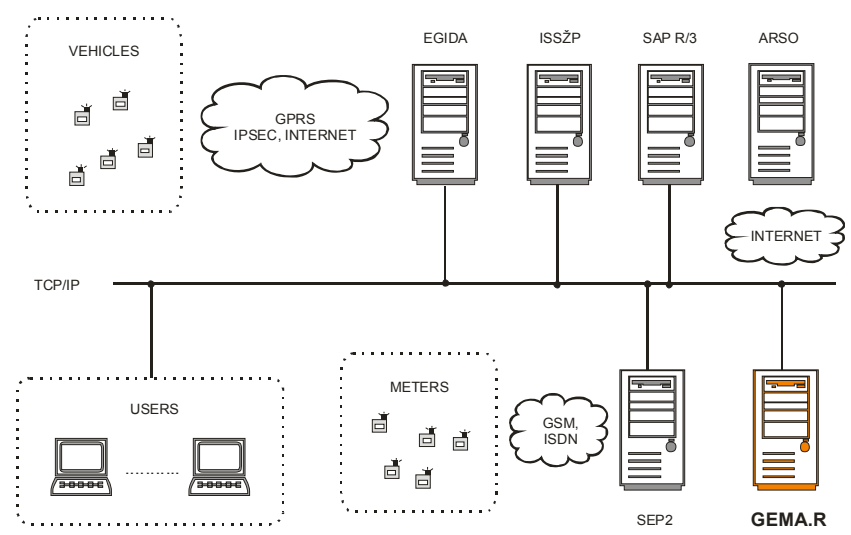

Figure 1: Communication block diagram.

The communication path is the same also when the engine leaves Slovenia. In this case roaming access to GPRS network is used.

Because the volume of data is low and speed of FTP connection high, transfer of data is performed typically in a few seconds. That is why the connection once established is almost always long enough to perform successful transfer.

If the connection cannot be established or if the connection falls during the data transfer, all data, unflagged as sent, are sent during the next successful connection.

To transfer data to GEMA.R EGIDA uses SOAP technology.

\section{Information system for railway energy management}

Genera Lynx's information system for energy management GEMA.R enables survey, analysing and forecasting of data that is relevant for energy consumption of railways traction and infrastructure units. 
It is a web-based software solution using Java. Users access it through an enterprise intranet or the Internet, mobile GSM and PDA devices. It uses standard SQL database - MS SQL Server and OLAP technology for data mining.

\subsection{Data sources}

The energy data exchange server is only one source for the information system for railway energy management.

Besides energy usage on the engines GEMA.R collects daily read outs of substations and railways buildings meters from SEP2.

GEMA.R exchanges information also with traffic management system (ISSŽP) to get data of train properties (mass, length, type of the train and number of locomotives) and timetables for purposes of analysing and forecasting.

To perform billing and cost analyses from ERP system (SAP R/3) relevant data are imported.

Furthermore, for energy efficiency analyses and consumption forecasting actual weather data and weather forecasts are imported from the Slovenian environmental agency's (ARSO) FTP data server.

Manual input of data for consumption points without AMR equipment is possible. This is the case for smaller consumers, where data are updated once per month.
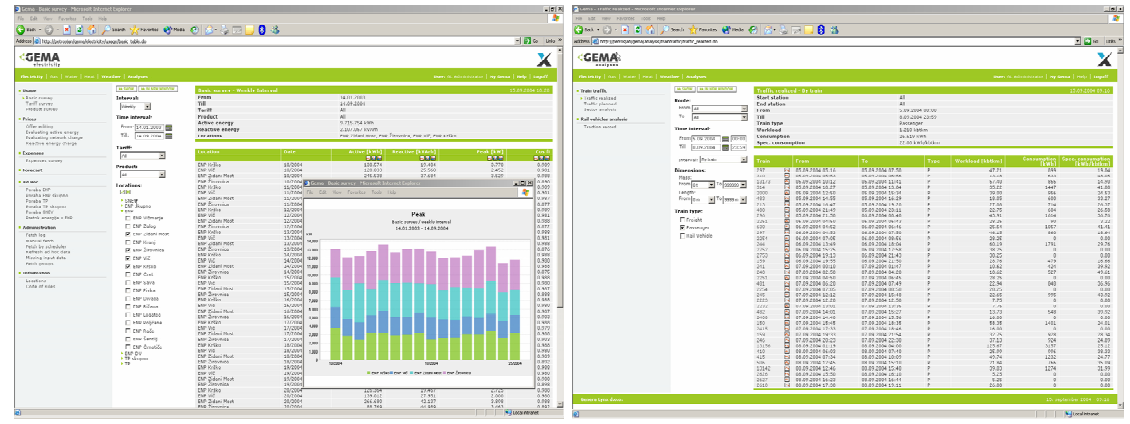

Figure 2: $\quad$ Screenshots of GEMA.R.

\subsection{Functionalities}

GEMA.R is based on the standard energy management system GEMA. It offers additional tools specifically developed for railways users.

Besides standard features of the energy management system GEMA (e.g. survey of energy consumption of any measurement point for chosen period and resolution, aggregation, price comparison, bill validation, etc.) within conjunction with TMS also total and specific energy consumption per each train or on daily, monthly and yearly basis are available. Apart from the train-based analyses also railway sections analyses are available with same features.

On the basis of timetables and energy related properties of archived journeys forecasts of energy consumption are calculated for a chosen train, for a particular substation and for all consumers together. 
Cargo train timetables are de-facto not fixed up to the minute and usually can be adapted in order to reduce energy costs.

Energy consumption forecasts are valuable data for lowering peak power demand on each substation. Besides these costs could be reduced with improved load profile (raising lowest and lowering highest 15 minutes or 1 hour consumption in a day) and to minimize the difference between the bought volume and consumed volume of electricity.

\section{Analysis of sample data}

\subsection{Background}

The aim of the analyses of the sample data from two characteristic sections was to get additional guidelines for further development of tools of the information system for an energy management system. For the purposes of energy management of Slovenian railways relevant factors for an optimal driving strategy on those sections was researched.

Regarding the existing literature coasting control could improve energy efficiency (Wong and Ho [1], Hwang Hee-Soo [2]). Regarding to Albrecht [3] the optimal driving regime consists of a maximum of four phases (driving with maximal acceleration, travelling with constant speed, coasting and operational braking to target with maximal deceleration). But as seen in Lukaszevicz [4] driver behaviour in the real world differs much from optimum driving strategy. An optimal compromise between trip time and energy consumption was researched with many tools [3, 2]; the study of Rongfang and Golovitcher [5] brings a comprehensive review of solving the problem of energy efficient train control. Those studies rely mostly on simulations and are not often supported by extensive experimental data.

In this work the primary focus is given to experimental determination of the influence of the degree of coasting on energy efficiency.

\subsection{Chosen sections}

Sample data form two sections, very different in topology but both with heavy cargo traffic, were observed; first from the Koper cargo station to Divača and another from the central cargo station Ljubljana Zalog to Zidani most. From Koper station to Divača a long steep hill occurs $(25 \%$ ) while the track form Ljubljana Zalog to Zidani most is characterised by a gentle decline.

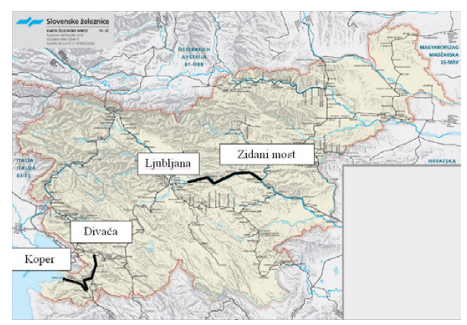

Figure 3: Slovenian railway network and sections chosen. 

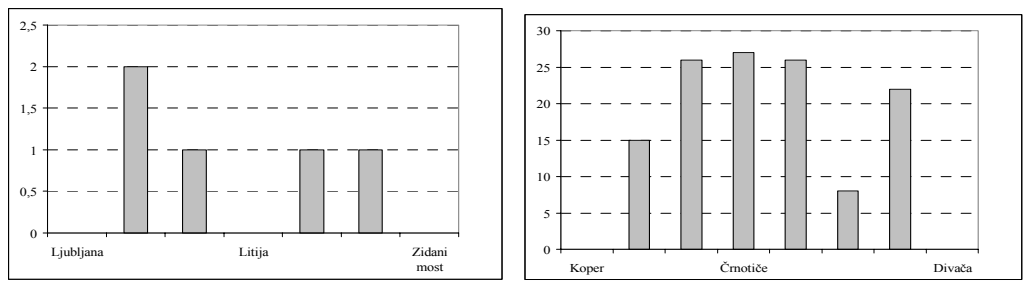

Figure 4: Characteristic resistance of the tracks (daN/t).

Because of the low resistance on the section Ljubljana Zalog - Zidani most one engine hauls a train with a mass up to 2000 tons. From Koper cargo station to Divača one engine is enough only for hauling trains lighter than 725 tons. When hauling heavier trains an engine with an on board meter device was combined with non-metered engines and complete energy consumption of the train was not available. That is why on this section only trains up to 725 tons were included in the analyses.

\subsection{Period and volume of measurement}

Data was collected from $1^{\text {st }}$ May 2005 to $31^{\text {st }}$ January 2006.

During that period more than 1000 trains with meters on board the engine drove on the observed sections. To assure comparable data only trains which entered the section in Ljubljana (Koper) and left the section in Zidani most (Divača) were included in the analyses. Regarding the above mentioned limitations this lowers the number of trains included to approximately 100 (10) trains.

\subsection{Influence of coasting ratio on specific consumption}

Coasting time is defined as the time of journey when power is equal to or lower than $1 \mathrm{kWh} / \mathrm{min}$ and the speed is higher than $3 \mathrm{~m} / \mathrm{s}$.

$$
\text { coasting ratio }=\frac{\text { coasting time }}{\text { total journey time }}
$$
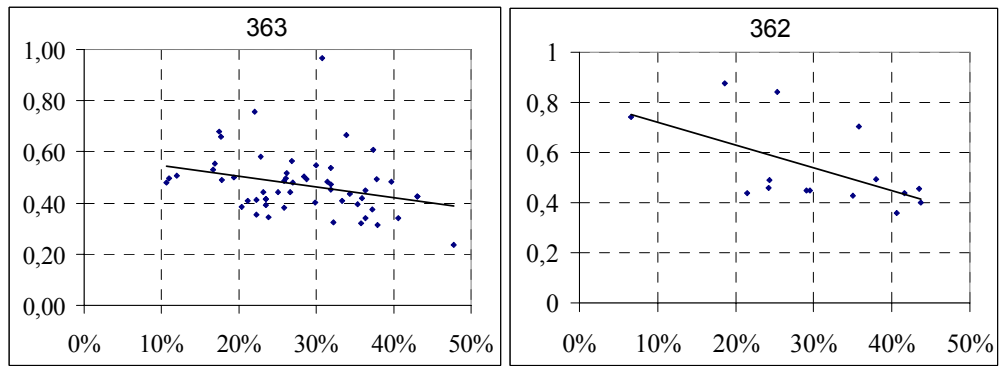

Figure 5: $\quad$ Specific consumption $(\mathrm{kWh} / \mathrm{ton})$ as a function of a coasting ratio (\%) on section Ljubljana - Zidani most for engines 363 and 362. 

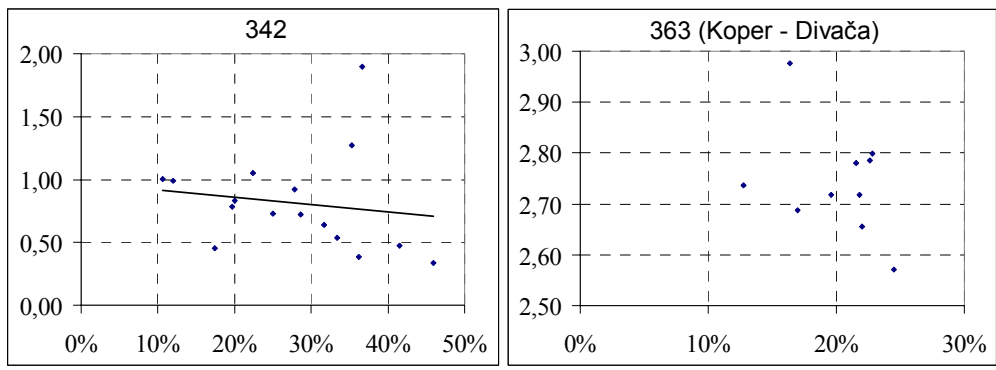

Figure 6: $\quad$ Specific consumption $(\mathrm{kWh} / \mathrm{ton})$ as a function of a coasting ratio (\%) on section Ljubljana - Zidani most for engine 342 and on section Koper - Divača for engine 363.
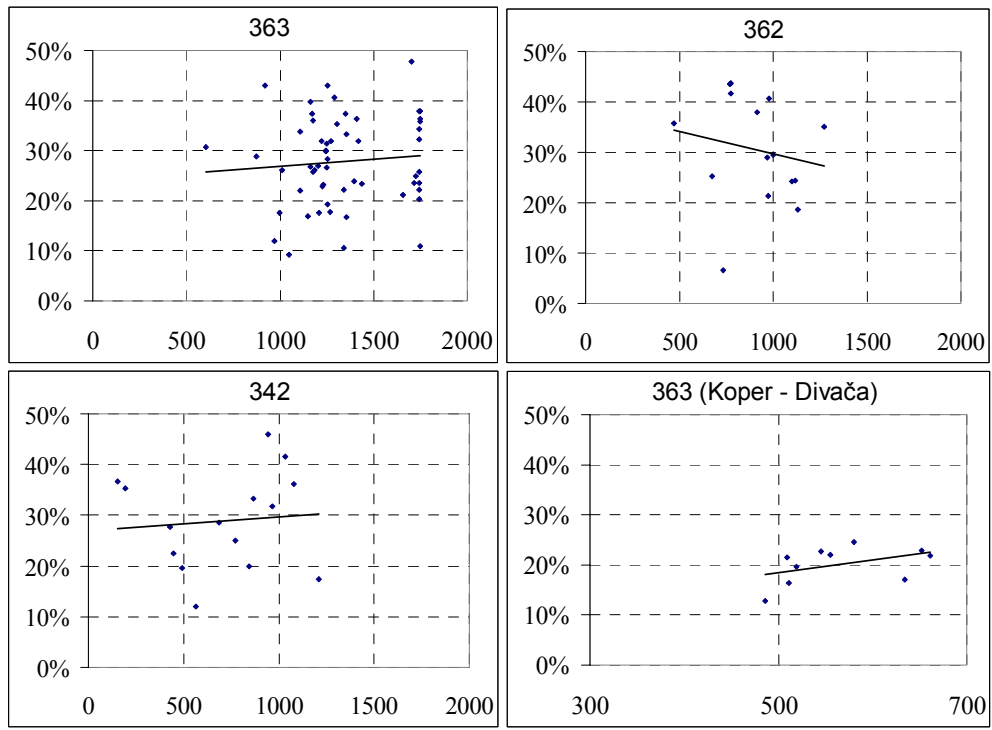

Figure 7: $\quad$ Ratio of coasting (\%) as mass (tons) function on sections Ljubljana - Zidani most and Koper - Divača.

\subsection{Influence of mass on coasting ratio}

While there are no tools for coasting point definition available for the drivers, the decision depends only on their experience. There is no evidence that drivers of heavier trains on either of the observed sections use their accumulated kinetic energy for a longer coasting period.

\subsection{Driving strategy of efficient and inefficient journey}

The driving strategy of two similar trains with significantly different consumptions are observed to define the characteristics of efficient driving. 
The journeys of both trains were performed between Ljubljana and Zidani most. Considering similar train properties, table 2 , it may be expected that the reason for a difference in consumption lies in different driving strategies.

Table 2: $\quad$ Trains characteristics.

\begin{tabular}{|c|c|c|c|c|c|c|c|}
\hline $\begin{array}{c}\text { train } \\
\text { id }\end{array}$ & $\begin{array}{c}\text { speed } \\
(\mathrm{m} / \mathrm{s})\end{array}$ & $\begin{array}{c}\text { consum. } \\
(\mathrm{kWh})\end{array}$ & $\begin{array}{c}\text { length } \\
(\mathrm{m})\end{array}$ & $\begin{array}{c}\text { mass } \\
(\text { ton })\end{array}$ & $\begin{array}{c}\text { coasting } \\
\text { ratio }\end{array}$ & $\begin{array}{c}\Sigma \Delta \text { speed } \\
(\mathrm{m} / \mathrm{s})\end{array}$ & $\begin{array}{c}\text { specific consum. } \\
(\mathrm{kWh} / \text { ton})\end{array}$ \\
\hline 7551 & 13.5 & 632 & 263 & 1253 & $28 \%$ & 151 & 0.50 \\
\hline 7579 & 13.6 & 533 & 260 & 1254 & $43 \%$ & 144 & 0.43 \\
\hline
\end{tabular}

$$
\Sigma \Delta \text { speed }=\sum_{n} a b s\left(\text { speed }_{i}-\text { speed }_{i-1}\right)
$$

where speed ${ }_{i}$ the is speed of the train in $i^{\text {th }}$ minute.

Train 7551 has significantly lower coasting ratio. This indicates longer period of powering and more intensive braking. A more dynamic journey is indicated also with higher sum of $\Delta$ speed, but here the difference is low.

The coasting pattern for both trains is similar, fig. 7, regarding the ends of the coasting periods. But train 7579 usually starts coasting earlier then train 7551 and the average coasting period is longer.

Considering similar properties of the train and a similar level of acceleration (fig. 8, table 2), which is - because recuperation of energy is not possible directly correlated to the energy needed, it could be assumed that the main reason for lower energy consumption of train 7579 is a higher coasting ratio. This higher ratio is achieved mainly by earlier starts of coasting periods.
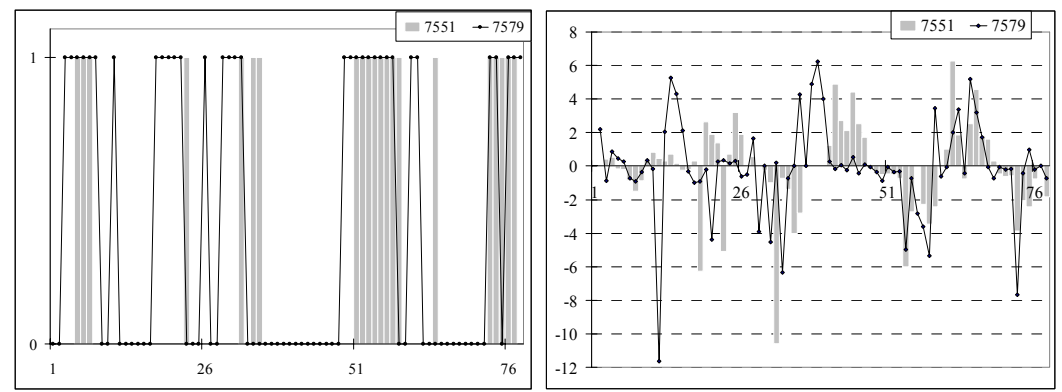

Figure 8: Coasting periods (when value $=1$ ) and acceleration $(\Delta \mathrm{m} / \mathrm{s})$ as a function of time (min) for trains 7551 and 7579.

\section{Conclusions}

An information system for energy management, implemented in Slovenian Railways, enables the reduction of energy related costs with lower price and lower energy usage. With a better knowledge of the load profile of the substations Railways improved their position on the energy market and lowered average price. 
With a comprehensive database of engines energy usage with simultaneous location and speed data and supplemented with information from the traffic management system extensive analyses of energy efficiency of a particular engine or the whole railway network are possible.

On the basis of data collected the traffic on the two sections has been examined here. The topology of the track limits coasting, but on both sections possibilities for further improvements of energy efficiency with longer coasting ratio have been shown.

Furthermore, two journeys with similar train properties but different energy consumption have been reviewed in detail with respect to driving strategies. The starting point of coasting has an important influence on energy consumption.

\section{References}

[1] K.K. Wong, T.K. Ho, Dynamic coast control of train movement with genetic algorithm, International Journal of System Science, Vol. 35, No. 13-14, pp. $835-846,2004$.

[2] Hwang Hee-Soo, Control Strategy for Optimal Compromise Between Trip Time and Energy Consumption in a High-Speed Railway, IEEE transactions on systems, man, cybernetics - part A: systems and humans, vol. 28, No. 6, pp. $791-802,1998$.

[3] T. Albrecht, Reducing power peaks and energy consumption in rail transit systems by simultaneous train running time control, Proc. of Computers in Railways IX: Computer Aided Design, Manufacture and Operation in the Railway and Other Advanced Mass Transit Systems (COMPRAIL 2004), eds. J. Allan, C.A. Brebbia, R.J. Hill G. Sciutto \& S. Sone, WIT Press: Southampton, Boston, pp. 885 - 895, 2004.

[4] Lukaszewiczm P., Energy consumption and running time for trains, Royal Institute of Technology, Stockholm, 2001.

[5] Rongfang Liu R., Golovitcher I. M.: Energy-efficient operation of rail vehicles, Transportation Research Part A 37, pp. 917 - 932, 2003. 